\title{
Associations of coffee drinking with physical performance in the oldest-old community-dwelling men The Helsinki Businessmen Study (HBS)
}

\author{
Satu K. Jyväkorpi ${ }^{1}$ (D) . Annele Urtamo ${ }^{1} \cdot$ Mika Kivimäki $^{1} \cdot$ Timo E. Strandberg $^{1,2}$
}

Received: 26 May 2020 / Accepted: 27 June 2020 / Published online: 8 July 2020

(c) The Author(s) 2020

\begin{abstract}
Background Habitual coffee drinking has been associated with lower risk of various chronic diseases linked to poor physical performance.

Objective We explored cross-sectional associations between coffee consumption and physical performance among oldestold community-dwelling men in the Helsinki Businessmen Study (HBS).

Methods A random sample of HBS survivors ( $n=126$, mean age 87 years) attended a clinic visit in 2017/2018, including measurements of body composition, physical performance [Short Physical Performance Battery (SPPB)], and cognition. Coffee consumption was retrieved from 3-day food diaries.

Results Coffee consumption was positively associated with higher gait speed $(p=0.003)$, SPPB score $(p=0.035)$, and chair rise points $(p=0.043)$. Association of coffee with gait speed remained after adjustment for age, waist circumference, physical activity, pulse rate, and high-sensitivity C-reactive protein.

Conclusion Higher coffee consumption was independently associated with better physical performance reflected as faster gait speed in oldest-old men.
\end{abstract}

Keywords Coffee $\cdot$ Gait speed $\cdot$ Physical performance $\cdot$ Appendicular lean mass · Oldest-old men

\section{Background}

Good physical function and performance are important for prevention of various health conditions and immobility among older adults [1]. In particular, low gait speed and chair stand have been associated with difficulties in performing activities of daily living (ADL) and poorer quality of life [2]. Knowledge of nutrition-related factors, physical function, and performance have been mainly limited to protein [3] and vitamin D intakes [4], specific foods such as fruit and vegetable and dairy products [5], and healthy dietary patterns such as the Mediterranean-type [6].

Satu K. Jyväkorpi

satu.jyvakorpi@gery.fi

1 Department of Medicine, Clinicum and Helsinki University Hospital, University of Helsinki, Tukholmankatu 8 B, 00014 Helsinki, Finland

2 Center for Life Course Health Research, University of Oulu, Oulu, Finland
Coffee is one of the most widely consumed beverages in the world. It has an ergogenic potential as it is high in caffeine, which is a natural stimulant [7]. Habitual coffee consumption has been linked to reduced risk of type 2 diabetes [8], cardiovascular diseases [9], and Alzheimer's disease [10], all of which are important contributors to impaired physical function and mobility [11].

A recent longitudinal study found that older coffee-drinking women had lower risk of immobility and ADL disability as compared to non-coffee drinkers [12]. Otherwise studies are scarce of physical performance, function, mobility, and coffee consumption in older people, especially men who on the average have better physical function than women of similar age.

\section{Aims}

Our objective was to investigate associations of coffee consumption with physical performance of oldest-old homedwelling men. 


\section{Methods}

In the Helsinki Businessmen Study (HBS), a socioeconomically homogenous cohort of men, born between 1919 and 1934, has been followed up since the 1960s [13]. In the present cross-sectional analysis, we report findings from the most recent clinic visit of a random sub-cohort of home-living survivors of HBS in 2017/2018. At the clinic visit, fasting venous samples were drawn, body mass index (BMI) was calculated $\left(\mathrm{kg} / \mathrm{m}^{2}\right)$, waist circumference measured, nutritional status assessed with the Mini Nutritional Assessment Short Form (MNA-SF) [14] and Short Physical Performance Battery (SPPB) test [15] performed as instructed, and gait speed (4-m walk, $\mathrm{m} / \mathrm{s}$ ) was measured. In addition, body composition analyzed using DXA-scans, and appendicular lean mass (ALM) $/ \mathrm{m}^{2}$ calculated according to the classification by Gould et al. [16] and resting pulse was measured. Cognition was measured using The Montreal Cognitive Assessment (MOCA) Screening tool [17]. Laboratory analyses included highsensitivity C-reactive protein (hs-CRP) to reflect inflammatory status. Daily coffee drinking, energy and macronutrient intakes, and protein distribution between daily meals were retrieved from 3-day food records. The participants were divided into three groups according to their daily coffee consumption (1) < 110 g, (2) 110-330 g, and (3) $>330 \mathrm{~g}$, and variables classified to the coffee categories accordingly.

\section{Statistical analyses}

We used descriptive statistics and analysis of covariance (ANCOVA) to investigate independent associations with coffee consumption. Adjustments were made for age, waist circumference, self-rated physical activity, pulse rate, and hs-CRP levels. Analyses were performed using the SPSS statistical program, version 24 (SPSS IBM, Armonk, NY, USA).

\section{Selection of the covariates}

Selection of covariates was based on previous research; waist circumference may indicate higher inflammatory load, metabolic problems, and poorer physical performance, inflammatory status measured by hs-CRP was selected as a covariate, because in previous research, high hs-CRP has been linked to lower physical performance in older people [18]. Pulse rate was selected as a covariate, because lower resting heart rate may indicate a higher cardiovascular fitness in the ANCOVA model.

\section{Results}

Of the 130 men who attended the clinic, 126 participants (mean age 87 years) returned 3-day food records. Median daily coffee consumption was $220 \mathrm{~g}$ (IQ range 126-376). In the ANOVA test of linearity, consumption of coffee was not significantly associated with age, BMI, waist circumference, MNA-SF, physical activity, cognition, or hs-CRP. Linear association of coffee consumption was observed with gait speed $(p=0.003)$, SPPB $(p=0.035)$ and chair rise points $(p=0.043)$ (Table 1).

Of nutritional variables, coffee drinking was linearly associated with higher plant protein $(p=0.047)$, carbohydrate $(p=0.036)$, and starch $(p=0.001)$ intakes (Table 2$)$. In addition, those who drank more coffee, consumed more protein during morning snack $(p=0.017)$.

Coffee consumption was associated with faster gait speed in ANCOVA model controlling for age, physical activity, pulse rate, hs-CRP, and waist circumference (Table 2).

\section{Discussion}

In the oldest-old community-dwelling men, higher consumption of coffee was associated with better physical performance and faster gait speed. This linear association remained statistically significant after adjusting for multiple covariates, a finding which is consistent with the hypothesis that moderate coffee drinking may be beneficial for physical performance in oldest-old men.

Coffee is naturally high in caffeine, which has an ergogenic potential. In fact, high amount of caffeine is known to enhance physical performance in athletes [7]. Although habitual coffee drinking can enhance performance, the daily amount of coffee consumption in our older participants was relatively low [median] about two small cups or $220 \mathrm{~g} /$ day. As some studies have reported that athletes did not get extra benefit for their performance by consuming much higher amounts of coffee per day [19], a recent study showed that even low acute dose of caffeine $(2 \mathrm{mg} /$ $\mathrm{kg}$ for $80 \mathrm{~kg}$ individual) that equal to approximately $200 \mathrm{~g}$ of coffee a day may produce substantial improvements in lower body muscle endurance [20]. Coffee also contains several bioactive compounds such as polyphenols and minerals and up to 1000 other bioactive components that could potentially affect performance and prevent chronic diseases. In observational studies, moderate coffee consumption has been associated with lower incidence of type 2 diabetes, and cardiovascular and Alzheimer's diseases, all known contributors to decline in physical function of older people [12]. Furthermore, a recent longitudinal study of older women found that coffee consumption of $\geq 2$ cups 
Table 1 Participant characteristics according to level of coffee consumption

\begin{tabular}{|c|c|c|c|c|}
\hline \multirow[t]{2}{*}{ Characteristics } & \multicolumn{4}{|l|}{ Coffee groups } \\
\hline & $\begin{array}{l}<110 \text { g of coffee } \\
\text { per day }(n=15)\end{array}$ & $\begin{array}{l}110-330 \mathrm{~g} \text { of coffee } \\
\text { per day }(n=74)\end{array}$ & $\begin{array}{l}>330 \mathrm{~g} \text { of coffee } \\
\text { per day }(n=37)\end{array}$ & $p$ value $^{\mathrm{a}}$ \\
\hline Age, years (SD) & $88.3(3.2)$ & $87.3(3.1)$ & $87.2(2.3)$ & 0.327 \\
\hline BMI, kg/m² (SD) & $25.4(2.3)$ & $25.7(2.8)$ & $26.4(2.7)$ & 0.141 \\
\hline Waist circumference (SD] & $103(7.7)$ & $101(8.5)$ & $102(9.8)$ & 0.997 \\
\hline MNA-SF (SD] & $13(1)$ & $13(1)$ & $13(1)$ & 0.682 \\
\hline Cognition, MOCA test & $22.4(2.6)$ & $23.6(2.3)$ & $23.2(2.1)$ & 0.584 \\
\hline Physically active, $\%$ & 47 & 41 & 54 & 0.379 \\
\hline hs-CRP (SD) & $3.1(3.5)$ & $2.7(3.3)$ & $2.1(2.5)$ & 0.252 \\
\hline SPPB (SD) & $8.4(3.4)$ & $9.3(2.3)$ & $9.9(2.1)$ & 0.035 \\
\hline Gait speed, m/s (SD) & $0.8(0.2)$ & $0.9(0.2)$ & $1.0(0.2)$ & 0.003 \\
\hline Chair rise, points (SD) & $2.27(1.5)$ & $2.51(1.3)$ & $2.97(1.1)$ & 0.043 \\
\hline Grip strength, kg (SD) & $28.7(8.5)$ & $31.5(7.3)$ & $30.2(6.8)$ & 0.856 \\
\hline $\mathrm{Alm} / \mathrm{m}^{2}(\mathrm{SD})$ & $6.97(0.7)$ & $7.04(0.7)$ & $7.30(0.7)$ & 0.144 \\
\hline \multicolumn{5}{|l|}{ Dietary intakes } \\
\hline Energy, kcal [SD) & $1456[335)$ & $1589[315)$ & $1639[438)$ & 0.123 \\
\hline Protein, g [SD) & $67(23)$ & $75(19)$ & $73(25)$ & 0.593 \\
\hline g/kg BW/day [SD) & $0.9(0.3)$ & $1.0(0.3)$ & $0.9(0.3)$ & 0.695 \\
\hline Vegetable protein, $\mathrm{g}[\mathrm{SD})$ & $19(10)$ & $21(6)$ & $23(7)$ & 0.047 \\
\hline Animal protein, g [SD) & $47(18)$ & $54(18)$ & $50(23)$ & 0.958 \\
\hline \multicolumn{5}{|l|}{ Protein distribution } \\
\hline Breakfast, g (SD) & $21(12)$ & $15(7)$ & $15(6)$ & 0.066 \\
\hline Morning snack, g (SD) & 0 & $3(5)$ & $5(8)$ & 0.017 \\
\hline Lunch, g (SD) & $21(11)$ & $23(14)$ & $23(14)$ & 0.597 \\
\hline Afternoon snack, g (SD) & $3(6)$ & $5(8)$ & $5(4)$ & 0.547 \\
\hline Dinner, g (SD) & $16(18)$ & $22(18)$ & $17(17)$ & 0.799 \\
\hline Evening snack, g (SD) & $5(7)$ & $7(7)$ & $7(6)$ & 0.364 \\
\hline Carbohydrate, g (SD) & $148(36)$ & $169(42)$ & $177(47)$ & 0.036 \\
\hline Starch, g (SD) & $69(19)$ & $84(21)$ & $95(32)$ & 0.001 \\
\hline Sugar, g (SD) & $21(7)$ & $26(14)$ & $23(11)$ & 0.918 \\
\hline Fiber, g (SD) & $21(7)$ & $21(8)$ & $24(10)$ & 0.148 \\
\hline Fat, g (SD) & $61(26)$ & $64(20)$ & $67(21)$ & 0.185 \\
\hline SFA, g (SD) & $22(7)$ & $22(7)$ & $22(9)$ & 0.797 \\
\hline MUFA, g (SD) & $23(15)$ & $24(11)$ & $25(10)$ & 0.490 \\
\hline PUFA, g (SD) & $10(6)$ & $12(4)$ & $13(6)$ & 0.076 \\
\hline
\end{tabular}

${ }^{a}$ The statistical significance of the hypotheses of linearity was evaluated for a trend using ANOVA and for non-evenly distributed variables with Kruskal-Wallis test, $\mathrm{SD}=$ standard deviation; BMI=body mass index; MNA-SF = Mini Nutritional Assessment Short Form; hs-CRP=high-sensitive C-reactive protein; $\mathrm{IQR}=$ Inter-quartile range; $\mathrm{SPPB}=$ Short Physical Performance Battery; $\mathrm{m} / \mathrm{s}=$ meters per second; $\mathrm{Alm}=$ appendicular lean mass; $\mathrm{m}^{2}=$ meter square; $\mathrm{d}=$ day; $\mathrm{kg}=$ kilograms; The statistical significance of the hypotheses of linearity was evaluated for a trend using ANOVA; BW = Body Weight; SFA = Saturated fatty acids; MUFA = monounsaturated fatty acids; PUFA = polyunsaturated fatty acids ${ }^{1}$ a day as compared to zero consumption was associated with reduced immobility [13]. The researchers also found that women with type 2 diabetes who consumed $\geq 2$ cups coffee a day had lower risk of ADL disability [13]. Our results in men support those findings as both gait speed and SPPB-test scores were higher in those who consumed more coffee. It is currently unknown whether contents of caffeine, polyphenol, mineral, other bioactive ingredients, or a combination of all of them contribute to the potential health effects of coffee consumption.

Among dietary factors, carbohydrate, starch, and plant protein intakes were higher among those who drank more coffee. Consequently, the participants drinking more coffee also consumed more cereal-based food such as bread, porridge, or salty pastries as compared to those who drank less. Coffee drinking was also associated with more snacking in 
Table 2 ANCOVA models of factors associated with gait speed

\begin{tabular}{lcccc}
\hline Model & $B$ & \multicolumn{2}{l}{$95 \%$ confidence interval } & $p$ value \\
\cline { 3 - 4 } & & Lower bound & Upper bound & \\
\hline Intercept & 2.631 & 1.424 & 3.838 & $<0.001$ \\
Coffee & 0.000 & 0.000 & 0.000 & 0.013 \\
Age & -0.014 & -0.026 & -0.001 & 0.032 \\
Waist circumference, cm & -0.004 & -0.008 & .001 & 0.088 \\
Physical activity yes vs. no & 0.096 & .023 & .169 & 0.011 \\
Pulse & -0.004 & -0.008 & -0.001 & 0.013 \\
hs-CRP & -0.016 & -0.028 & -0.005 & 0.005 \\
Adjusted $R^{2}$ & $\mathbf{0 . 2 4 4}$ & & & \\
\hline
\end{tabular}

Bold value indicates the amount of observed variation that can be explained by the model's inputs $B M I$ body mass index, $H s$ - $C R P$ high-sensitivity C-reactive protein, $R^{2} R$ squared our study, especially snacking between breakfast and lunch was more frequent among those who drank more coffee. In line with these findings, higher coffee consumption tended to be associated with higher energy intake, higher BMI, and greater appendicular lean mass. Then, a question arises whether higher coffee consumption leads to better performance via increased energy content of the diets and better nutrition in these oldest-old men.

\section{Strengths and limitations}

The strengths of our study are the robust findings of coffee consumption and physical performance, although our study sample was relatively small. Obviously, the surviving participants of HBS differ in many ways from the general older population due to their high socioeconomic status. There is interesting evidence that sex would modify the association between coffee consumption and cognition, with stronger effect among females [21]. This could also apply to physical performance, but unfortunately potential differences between sexes could not be compared in our study. The cross-sectional design of the study prevents drawing conclusions about causal relationships. It also is possible that the observed associations are attributable to bias and confounding by unmeasured or imprecisely measured risk factors. Finally, hypersensitivity or intolerance to coffee may be linked to health problems, contributing to a spurious association between coffee consumption and physical performance.

\section{Conclusion}

We observed an independent association between higher consumption of coffee and better physical performance and faster gait speed, which are important determinants of health and survival of older people. As coffee intakes are modifiable, these findings encourage further intervention studies to determine whether moderate coffee drinking could be recommended as part of a healthy diet for the oldest-old.

Acknowledgments Open access funding provided by University of Helsinki including Helsinki University Central Hospital.

Author contributions SKJ designed and performed out the data analysis, and AU carried out the clinic visits. All authors contributed to writing of the manuscript and approved the final version.

Funding This work was supported by Foundation of Nutrition Research, VTR funding of the Helsinki University Hospital (EVO), Helsinki University Hospital Internal Medicine and Rehabilitation and Academy of Finland, Grant number 311492, Nord Forsk and Helsinki Institute of Life Science. The sponsors did not have any role in the study design, analysis, or interpretation of data, nor in writing the report or the decision to submit this article. The authors were independent researchers not associated with the funders.

\section{Compliance with ethical standards}

Conflict of interest SKJ: reports no conflict of interest. AU: reports no conflict of interest. MK: reports grants from Nord Forsk, the Academy of Finland, and Helsinki Institute of Life Science, during the conduct of the study. TES: reports having various educational and consultative cooperation with several companies, including Nutricia, Abbott, Amgen, Merck, Pfizer, Novartis, and Novo-Nordisk; a minor amount of stock in Orion Pharma; and is a board member and former president of executive board of European Union Geriatric Medicine Society which has cooperation also with the nutrition industry.

Ethics approval The research was conducted according to the Declaration of Helsinki. The study protocol was approved by the Ethics Committee of the Helsinki University Hospital, Department of Medi- 
cine and the study is registered with ClinicalTrials.gov identifier: NCT02526082.

Consent to participate (include appropriate statements) All participants signed an informed consent.

Availability of data and material (data transparency) The data will be made available upon request to TES.

Open Access This article is licensed under a Creative Commons Attribution 4.0 International License, which permits use, sharing, adaptation, distribution and reproduction in any medium or format, as long as you give appropriate credit to the original author(s) and the source, provide a link to the Creative Commons licence, and indicate if changes were made. The images or other third party material in this article are included in the article's Creative Commons licence, unless indicated otherwise in a credit line to the material. If material is not included in the article's Creative Commons licence and your intended use is not permitted by statutory regulation or exceeds the permitted use, you will need to obtain permission directly from the copyright holder. To view a copy of this licence, visit http://creativecommons.org/licenses/by/4.0/.

\section{References}

1. Mijnarends DM, Luiking YC, Halfens R, Evers S, Lenaerts E, Verlaan S, Wallace M, Schols J, Meijers J (2018) Muscle, health and costs: a glance at their relationship. J Nutr Health Aging 22:766-773. https://doi.org/10.1007/s12603-018-1058-9

2. van Lummel RC, Walgaard S, Pijnappels M, Elders PJM, GarciaAymerich J, van Dieen JH, Beek PJ (2015) Physical performance and physical activity in older adults: associated but separate domains of physical function in old age. PLoS ONE. https://doi. org/10.1371/journal.pone.0144048

3. Tieland M, van de Rest O, Dirks ML, van der Zwaluw N, Mensink M, van Loon LJ, de Groot LC (2012) Protein supplementation improves physical performance in frail elderly people: a randomized, double-blind, placebo-controlled trial. J Am Med Dir Assoc 13:720-726

4. Dewansingh P, Melse-Boonstra A, Krijnen WP, van der Schans CP, Jager-Wittenaar H, van den Heuvel EGHM (2018) Supplemental protein from dairy products increases body weight and vitamin D improves physical performance in older adults: a systematic review and meta-analysis. Nutr Res 49:1-22

5. Houston DK, Stevens J, Cai J, Haines PS (2005) Dairy, fruit, and vegetable intakes and functional limitations and disability in a biracial cohort: the atherosclerosis risk in communities study. Am J Clin Nutr 81:515-522

6. Struijk EA, Guallar-Castillon P, Rodriguez-Artalejo F, Lopez Garcia $E$ (2016) Mediterranean dietary patterns and impaired physical function in older adults. J Gerontol A Biol Sci Med Sci. https:// doi.org/10.1093/gerona/glw208

7. Higgins S, Straight CR, Lewis RD (2016) The Effects of preexercise caffeinated coffee ingestion on endurance performance: an evidence-based review. Int J Sport Nutr Exerc Metab. https://doi. org/10.1123/ijsnem.2015-0147

8. Ding M, Bhupathiraju SN, Chen M, van Dam RM, Hu FB (2014) Caffeinated and decaffeinated coffee consumption and risk of type 2 diabetes: a systematic review and a dose-response meta-analysis. Diabetes Care 37:569-586

9. Ding M, Bhupathiraju SN, Satija A, van Dam RM, Hu FB (2014) Long-term coffee consumption and risk of cardiovascular disease: a systematic review and a dose-response meta-analysis of prospective cohort studies. Circulation 129:643-659

10. Eskelinen MH, Ngandu T, Tuomilehto J, Soininen H, Kivipelto M (2009) Midlife coffee and tea drinking and the risk of late-life dementia: a population-based CAIDE study. J Alzheimers Dis 16:85-91

11. Stuck AE, Walthert JM, Nikolaus T, Büla CJ, Hohmann C, Beck JC (1999) Risk factors for functional status decline in community living elderly people: a systematic literature review. Soc Sci Med 48:445-469

12. Machado-Fragua MD, Struijk EA, Graciani A, Guallar-Castillon P, Rodríguez-Artalejo F, Lopez-Garcia E (2019) Coffee consumption and risk of physical function impairment, frailty and disability in older adults. Eur J Nutr 58:1415-1427

13. Strandberg TE, Salomaa V, Strandberg AY, Vanhanen H, Sarna S, Pitkälä K, Rantanen K, Savela S, Pienimäki T, Huohvanainen E, Stenholm S, Räikkönen K, Tilvis RS, Tienari PJ, Huttunen J (1074h) Cohort profile: The Helsinki Businessmen Study (HBS). Int J Epidemiol 45:1074-1074h

14. Vellas B, Guigoz Y, Garry PJ, Nourhashemi D, Bennahum D, Launque S, Albarede L (1999) The Mini Nutritional Assessment [MNA] and its use in grading the nutritional state of elderly patients. Nutrition 15:116-122

15. Guralnik JM, Simonsick EM, Ferrucci L, Glynn RJ, Berkman LF, Blazer DG, Scherr PA, Wallace RB (1994) A short physical performance battery assessing lower extremity function: association with self-reported disability and prediction of mortality and nursing home admission. J Gerontol 1949:M85-94

16. Gould H, Brennan SL, Kotowicz MA, Nicholson GC, Pasco JA (2014) Total and appendicular lean mass reference ranges for Australian men and women: the Geelong osteoporosis study. Calcif Tissue Int 94:363-372

17. Julayanont $P$, Tangwongchai $S$, Hemrungrojn S, Tunvirachaisakul C, Phanthumchinda K, Hongsawat J, Suwichanarakul P, Thanasirorat S, Nasreddine ZS (2015) The Montreal cognitive assessment-basic: a screening tool for mild cognitive impairment in illiterate and low-educated elderly adults. J Am Geriatr Soc 63:2550-2554. https://doi.org/10.1111/jgs.13820

18. Cesari M, Penninx BWJH, Pahor M, Lauretani F, Corsi AM, Williams GR, Guralnik JM, Ferrucci L (2004) Inflammatory markers and physical performance in older persons: the in CHIANTI study. J Gerontol 3:242-248

19. Tunnicliffe JM, Erdman KA, Reimer RA, Lun V, Shearer J (2008) Consumption of dietary caffeine and coffee in physically active populations: physiological interactions. Nutr Metab 33:1301-1310

20. Grgic J, Sabol F, Venier S, Mikulic I, Bratkovic N, Schoenfeld BJ, Pickering C, Bishop DJ, Pedisic Z, Miculic P (2019) What dose of caffeine to use: acute effects of 3 doses of caffeine on muscle endurance and strength. Int J Sports Physiol Perform. https://doi. org/10.1123/ijspp.2019-0433

21. Richie K, Carriere A, de Mendonca F, Porter JF, Dartigues O, Rouaud P, Barberger-Gateau M, Ancelin L (2007) The neuroprotective effects of caffeine-a prospective population study (the Three City Study). Neurology 69:536-545. https://doi. org/10.1212/01.wnl.0000266670.35219.0c

Publisher's Note Springer Nature remains neutral with regard to jurisdictional claims in published maps and institutional affiliations. 